
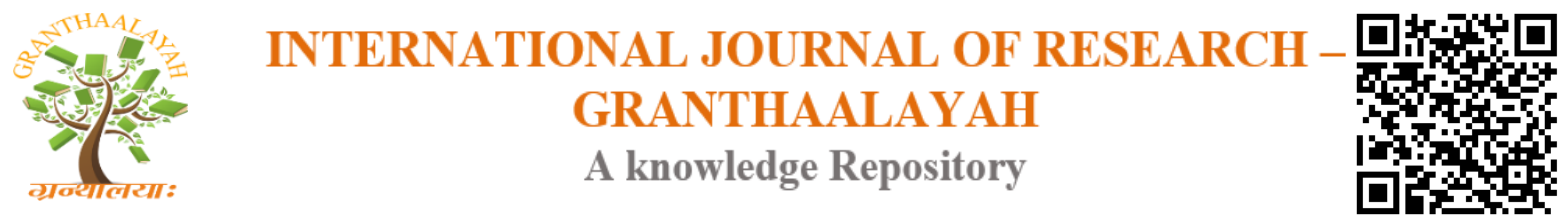

Science

\title{
THE EFFECTIVENESS OF E-IPCR SYSTEM AS A TOOL FOR MANAGING FACULTY PERFORMANCE EVALUATION AT THE RAMON MAGSAYSAY TECHNOLOGICAL UNIVERSITY MAIN CAMPUS IBA ZAMBALES PHILIPPINES: A BASIS FOR ENHANCEMENT
}

\author{
Menchie A. Dela Cruz, Ph.D.TE *1 \\ ${ }^{*}$ Associate Professor, College of Communication and Information Technology Ramon \\ Magsaysay Technological University, Iba Zambales
}

\begin{abstract}
Electronic system is the doorway to fast and efficient transactions in most of our daily undertakings today. Such transactions cover quality output for a huge majority of businesses, society and institutions that include state universities and colleges.

This study aimed to determine the level of effectiveness of electronic Individual Performance Commitment and Review (e-IPCR) system that was developed, tested and implemented as a tool of managing faculty performance evaluation for the Ramon Magsaysay Technological University Zambales (RMTU). It was also designed to assess the user's level of acceptability for continuously adopting the system and determine what additional features are to be integrated in the system for enhancement. This study made use of the causal comparative descriptive research to determine the cause of differences that already exist between or among group of individuals. This involved two groups of respondents: 1) The college deans and 2) faculty of the RMTU. The groups were selected using purposive sampling technique. The De Lone and McLean Success Models were used as bases for system effectiveness measurement-- information quality, system quality, service quality, intention to use, user satisfaction, and net benefits. The study revealed that e-IPCR System that was developed, tested and implemented for RMTU is "Effective" in terms of Information Quality, Systems Quality, Service Quality, Intention to Use, User Satisfaction and Net Benefits; and the user's level of acceptability to continually adopt the system is described as "Acceptable" using the same, system with database working on Local Area Networks ranked as the top preference and priority of the user for integration in the system.
\end{abstract}

Keywords: Effectiveness; Systems Quality; Service Quality; User Satisfaction; Net Benefits.

Cite This Article: Menchie A. Dela Cruz. (2018). "THE EFFECTIVENESS OF E-IPCR SYSTEM AS A TOOL FOR MANAGING FACULTY PERFORMANCE EVALUATION AT THE RAMON MAGSAYSAY TECHNOLOGICAL UNIVERSITY MAIN CAMPUS IBA ZAMBALES PHILIPPINES: A BASIS FOR ENHANCEMENT." International Journal of Research - Granthaalayah, 6(8), 93-104. 10.29121/granthaalayah.v6.i8.2018.1265. 


\section{Introduction}

The Ramon Magsaysay Technological University (RMTU), as an educational system progressed from large decentralized structures to a more centralized one. Bringing services with utmost quality and dedication is one of the commitments of the institution while transforming into a system with high standards, efficient management and high faculty performance achievement. To sustain transformation, the university includes on its master plan strategies that support more efficient school management and performance evaluation system. The Individual Performance Commitment and Review (IPCR) system is a vital part of the commitment on improving the performance of RMTU faculty. It is a mandate of Civil Service Commission, as stipulated in the constitution, which is to adopt measures promoting efficiency in the civil service (Section 3, Art. IX-B, Phil. Const.). The implementation of the SPMS is pursuant to CSC Memorandum Circular No. 06, s. 2012 and CSC Resolution No. 1200481, promulgated on March 16, 2012. Accordingly, this shall set the internal policies and procedures in the implementation of Individual Performance Commitment and Review System in the University. It shall also serve as a foundation for achieving the goal to increased employee's achievement and performance.

The Electronic Individual Performance Commitment and Review (e-IPCR) system developed, tested and implemented as a tool in managing faculty performance in RMTU served as an evaluation strategy for assessing individual collective performance within the academic unit of the university. The institution established a mechanism for setting standards to align individual objectives to agency department/college objectives.

\section{Theoretical Framework}

According to the DeLone and McLean (1992) Success Model, there are six interdependent variables, which are theoretically connected, (1) the Systems Quality, (2) Information Quality, (3) Service Quality, (4) Intension to Use, (5) User Satisfaction and (6) Net Benefits. Systems Quality measures the quality of the information processing within the system. The IS output is measured by Information Quality. Intention to Use is the demand or consumption of Information System (IS) output. On the other hand, User Satisfaction describes the reaction of the recipient to the use of the IS output. Finally, Net Benefits describes the influence of Information on overall organizational success.

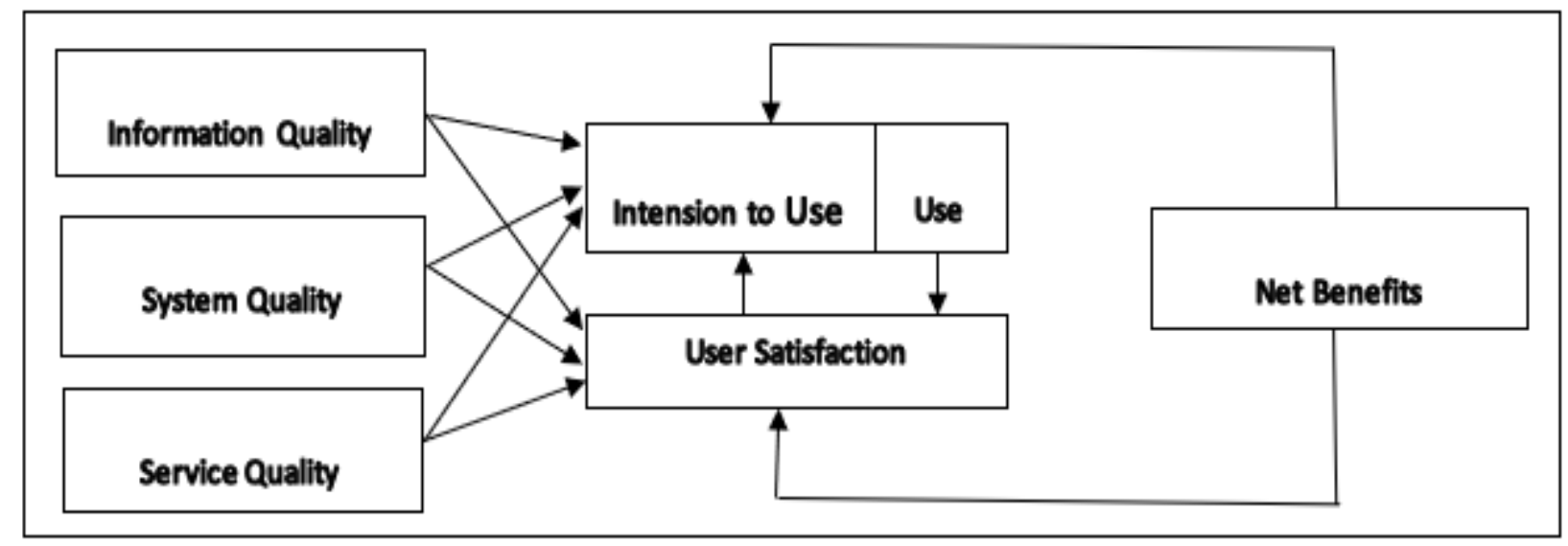

Figure 1: De Lone and McLean Success Model 


\section{Conceptual Model}

The main thrust of the study is to determine the effectiveness of e-IPCR system as a tool for managing faculty performance evaluation for the Ramon Magsaysay Technological University Main Campus in Iba, Zambales.

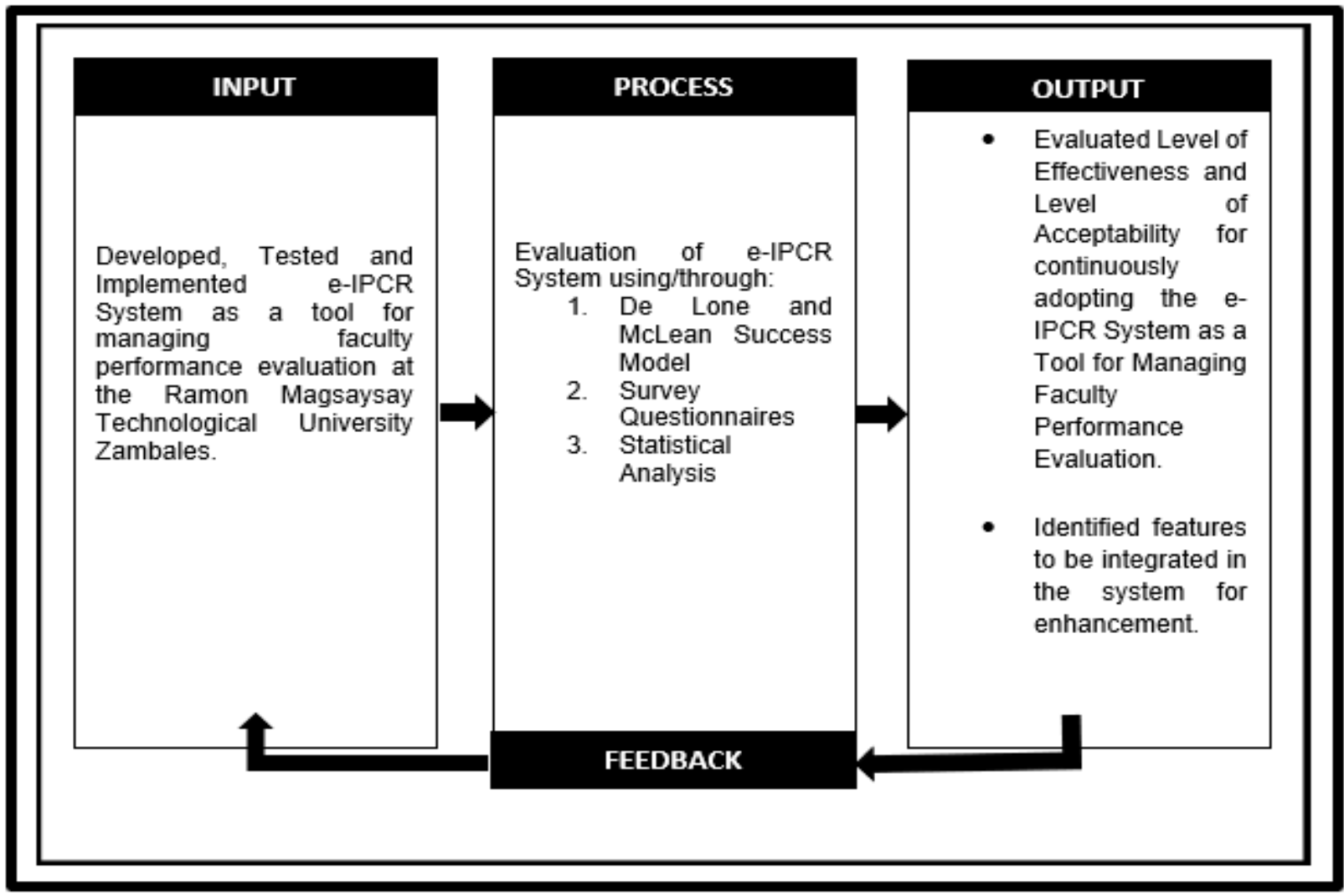

Figure 2: (Input-Process-Output) Best illustrates the variables used in the study

The Input variable used in this study is the developed, tested and implemented e-IPCR System as a tool for managing faculty performance evaluation for RMTU Main Campus, Iba, Zambales.

The Process variable is the evaluation of the system's level of effectiveness using the De Lone and McLean success model; and distribution and retrieval of survey questionnaires for data gathering and statistical analysis to obtain usable and useful information.

The Output variable is the evaluated level of effectiveness and level of acceptability for continuously adopting the system as a tool for managing faculty performance evaluation and identified what additional features have to be integrated in the system for a more enhanced system.

Feedback from the respondents is may be evaluated for future enhancement of the system.

\section{Statement of the Problem}

This research study aimed to determine the level of effectiveness of e-IPCR system developed, tested and implemented as a tool for managing faculty performance evaluation at the RMTU Main 
Campus Zambales; the level of acceptability of users to continuously adopt the system; and identify what features are to have to be integrated in the system for more enhanced e-IPCR system. Specifically, the study sought to answer the following questions:

1) What is the level of effectiveness of e-IPCR system as a tool for managing faculty performance evaluation at the RMTU Main Campus, Iba, Zambales as evaluated by the college deans and faculty respondents using the De Lone and McLean Success Model?

- Information Quality,

- System Quality

- Service Quality

- Intention to Use

- User Satisfaction

- Net Benefits

2) What is the level of acceptability of the college deans and faculty respondents for continuously adopting the e-IPCR system as a tool for managing faculty performance evaluation using the criteria in Problem 1 ?

3) What features have to be included in the e-IPCR system as a tool of managing faculty performance evaluation for university as identified by the college deans and faculty respondents for enhancement?

4) What is the substantial difference between the evaluation of the college deans and faculty respondents on the level of effectiveness of e-IPCR system as a tool for managing faculty performance evaluation for university using the criteria in problem 1 ?

5) What is the substantial difference between the evaluation of the college deans and faculty respondents on the level of acceptability for continuously adopting the e-IPCR system as a tool for managing faculty performance evaluation for university using the criteria in problem 1 ?

\section{Hypotheses}

To make the data more lucid, the following hypotheses were tested:

1) There is no substantial difference between the evaluation of college deans and faculty respondents on the effectiveness of e-IPCR system as a tool for managing faculty performance evaluation for RMTU Main Campus, Iba, Zambales using the criteria in problem 1.

2) There is no substantial difference between the evaluation of the college deans and faculty respondents on the level of acceptability for continuously adopting the e-IPCR system as a tool of managing faculty performance evaluation for the university using the criteria in problem 1.

\section{Research Methodology}

This study made use of causal comparative descriptive research to determine the cause and consequences of differences that already exist between or among group of individuals. The researcher selected two groups of participants/respondents: 1) the experimental and 2) the control groups, more accurately referred to as comparison groups. One group possesses a characteristic that the other does not. Each group has the characteristic, but to differing degrees or amounts. 


\section{Sampling Scheme}

A considerable number of respondents was used in this study. It consists of eight (8) college dean respondents and sixty-four (64) faculty respondents, with a total of seventy-two (72) respondents from Ramon Magsaysay Technological University Main Campus, Iba, Zambales. These respondents were chosen using the Purposive Sampling Technique, as based on the identified group of respondents.

Table 1: Frequency and Percentage Distribution of Respondents

\begin{tabular}{|l|l|l|l|}
\hline Respondent & Population Frame & $\begin{array}{l}\text { Sample } \\
\text { Frame }\end{array}$ & $\begin{array}{l}\text { Sample } \\
\text { Percentage }\end{array}$ \\
\hline College Deans & 10 & 8 & $80.00 \%$ \\
\hline Faculty & 279 & 64 & $22.94 \%$ \\
\hline TOTAL & $\mathbf{2 8 9}$ & $\mathbf{7 2}$ & $\mathbf{2 4 . 9 1 \%}$ \\
\hline
\end{tabular}

\section{Description of the Respondents}

RMTU Zambales consists of several campuses where seven (7) of the campuses are being managed by campus directors while the main campus is being run by college deans. A total population frame of two hundred eighty-nine (289) was set of which ten (10) come from college deans while two hundred seventy-nine (279) are from the faculty. College Dean Respondents pertain to the group of respondents who are either a faculty member or administrator of the institution and considered as the main user of the e-IPCR system as tool of managing faculty performance evaluation. On the other hand, Faculty Respondents pertain to the group of respondents evaluated by the college dean using the same system.

\section{Research Instrument}

This study was conducted at the Ramon Magsaysay Technological University Main Campus at Iba, Zambales. The researcher has made use of a structured questionnaire that served as one of the important survey instrument and means of gathering first-hand information to the respondents-1) the college deans and 2) the faculty members who were directly involved and affected in the implementation of the e-IPCR system.

\section{Statistical Treatment of Data}

Data gathered were tallied, analyzed and interpreted and were treated using routine statistical procedures with the use of Microsoft Excel or SPSS program. The Likert Scale, a technique to increase the variation of the possible scores, was used interpret the responses to the information systems performance. Dedekind cuts was also used in the construction of the real numbers (Weight), Soare (1969).

Likert scale with Dedekind cuts employed the table below:

\begin{tabular}{|l|l|l|l|l|l|}
\hline Point & Weight & Symbol & Descriptive Rating & Symbol & Descriptive Rating \\
\hline 5 & $4.50-5.00$ & VE & Very Effective & VA & Very Acceptable \\
\hline
\end{tabular}




\begin{tabular}{|l|l|l|l|l|l|}
\hline 4 & $3.50-4.49$ & E & Effective & A & Acceptable \\
\hline 3 & $2.50-3.49$ & ME & Moderately Effective & MA & Moderately Acceptable \\
\hline 2 & $1.50-2.49$ & SE & Slightly Effective & SA & Slightly Acceptable \\
\hline 1 & $1.00-1.49$ & NE & Not Effective & NA & Not Acceptable \\
\hline
\end{tabular}

To interpret the data effectively, the researcher employed the following statistical treatment:

Percentage. Employed to determine the frequency counts and percentage distribution of personally related variable of the respondents using the formula shown below (Punzalan, 1992).

Weighted Arithmetic Mean. Used to assess the respondents regarding the level of effectiveness and acceptability for continuously adopting the system.

T-test. A type of inferential statistics, it is used to determine the significant difference between the means of two groups. (Gosset, 1905).

\section{Results and Discussions}

Summary of respondents' evaluation on the level of effectiveness of e-IPCR system as a tool for managing faculty performance evaluation for RMTU Main Campus, Iba, Zambales.

Chart 1 below represents the Summary of Respondents' Evaluation on the Level of Effectiveness of e-IPCR system as a Tool for Managing Faculty Performance Evaluation for RMTU Main Campus, Iba, Zambales.

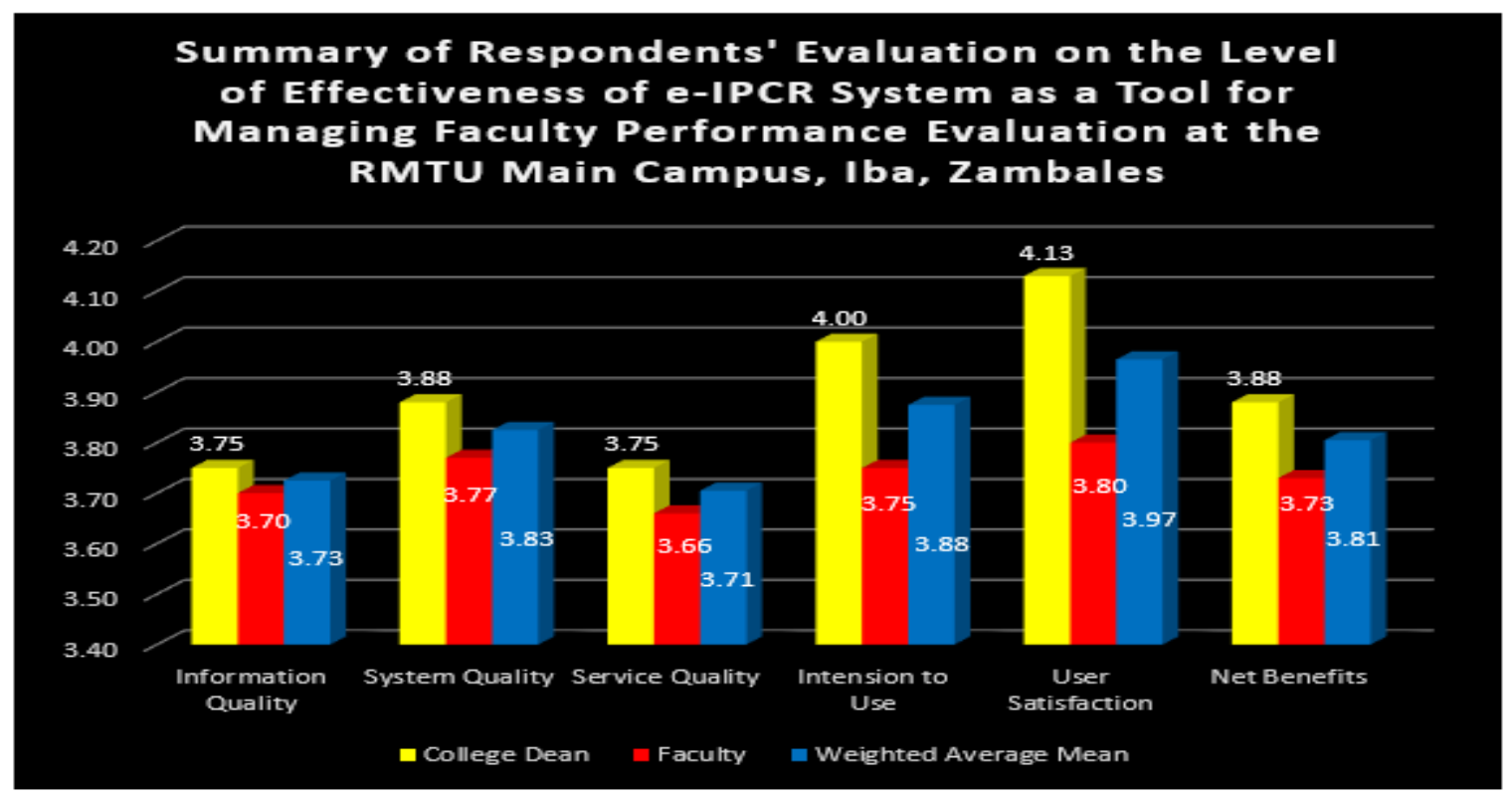

Chart 1

The college dean and faculty respondents evaluated the level of effectiveness of e-IPCR system as "Effective". This shows that respondents are satisfied with their actual experience in using the system particularly the accessibility, accuracy, validity, compatibility and timeliness of the system. 
This also reveals that the e-IPCR system helped the respondents, especially the college deans, in managing faculty evaluation with ease and accuracy.

Summary of respondents' evaluation on the level of acceptability to adopt the e-IPCR system as a tool of managing faculty performance evaluation for RMTU Main Campus, Iba, Zambales.

Chart 2 below represents the summary of respondents' evaluation on the level of acceptability for continuously adopting the e-IPCR system as a tool of managing faculty performance evaluation for RMTU Main Campus, Iba, Zambales.

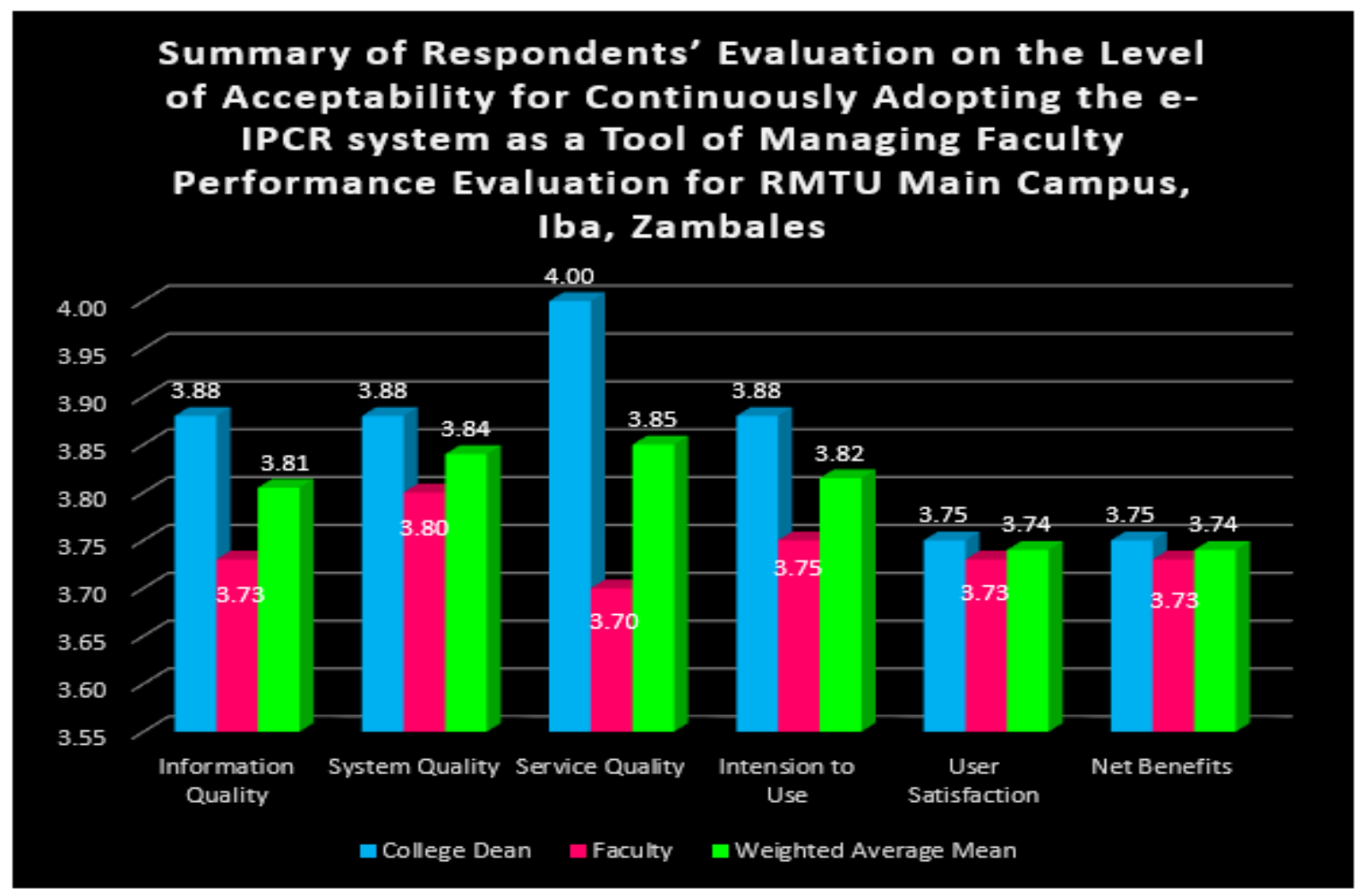

Chart 2

Both respondents evaluated the level of acceptability for continuously adopting the e-IPCR system as "Acceptable". This result could be ascribed to the fact that the e-IPCR system is better to use for its high system quality, generates accurate information, provides quality service, and delivers user's satisfaction to achieve its overall net benefits.

Summary of respondents' evaluation on the features to be integrate in the e-IPCR system for enhancement as a tool of managing faculty performance evaluation for RMTU Main Campus, Iba, Zambales.

Chart 3 below represents the Summary of respondents' evaluation on the features to be integrate in the e-IPCR for more enhanced system as a tool for managing faculty performance evaluation for RMTU Main Campus, Iba, Zambales. 


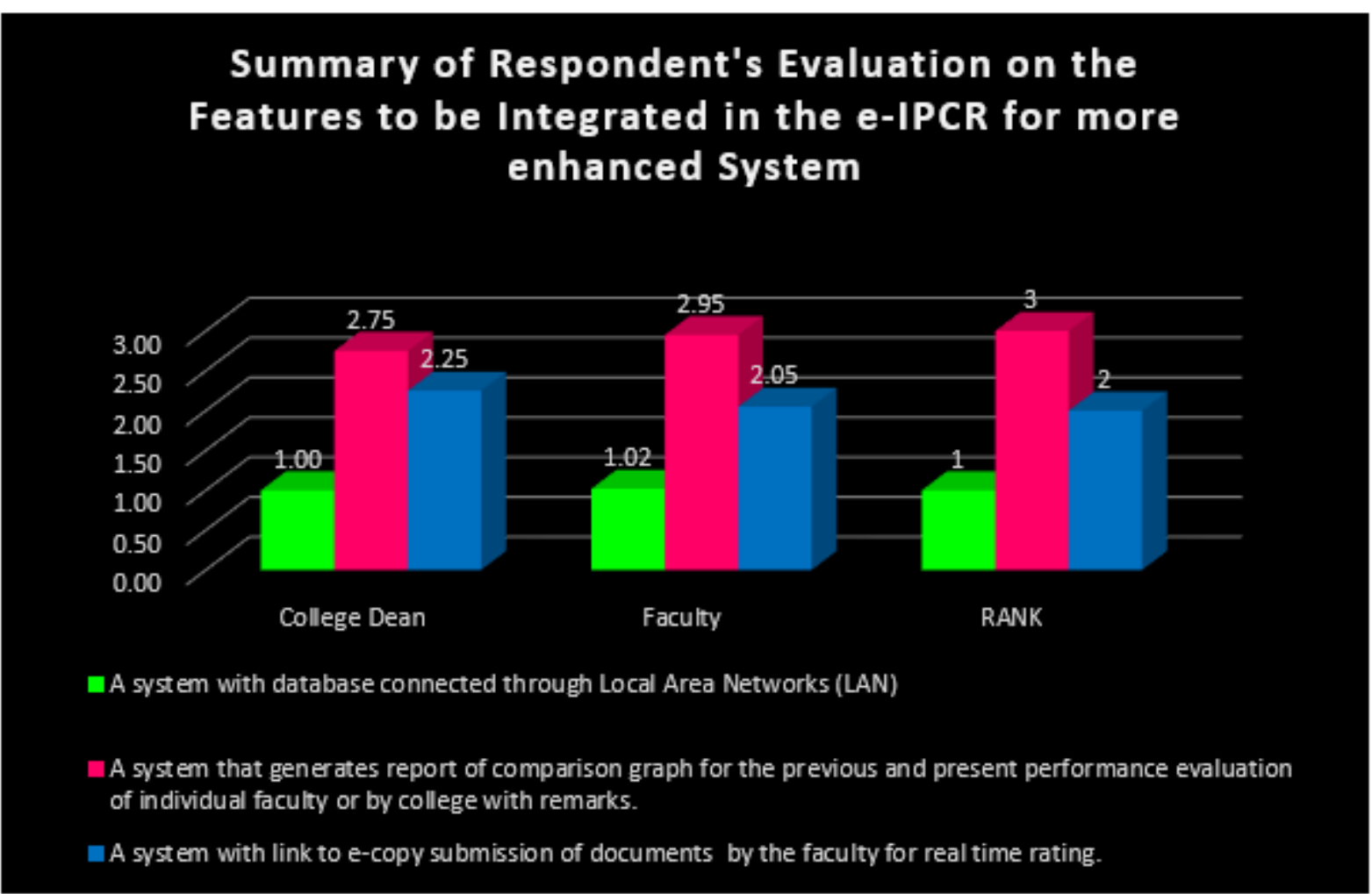

Chart 3

Both groups of respondents indicated that the top most feature to integrate in the system is a system with database connected through local area networks. It reveals that the respondents truly identified the usability and functions of a system with database that performs storing and retrieving of records easily and accurately, generates reports with comparison graph of the previous to the present faculty performance evaluation and links to the system for real time submission of e-copy by the faculty.

Substantial difference between the evaluation of the college deans and faculty respondents on the level of effectiveness of e-IPCR system as a tool of managing faculty performance evaluation for RMTU Main Campus, Iba, Zambales.

Chart 4 below represents the substantial difference between the evaluation of the respondents composed of college deans and faculty members on the level of effectiveness of e-IPCR system as a tool of managing faculty performance evaluation for RMTU Main Campus, Iba, Zambales 


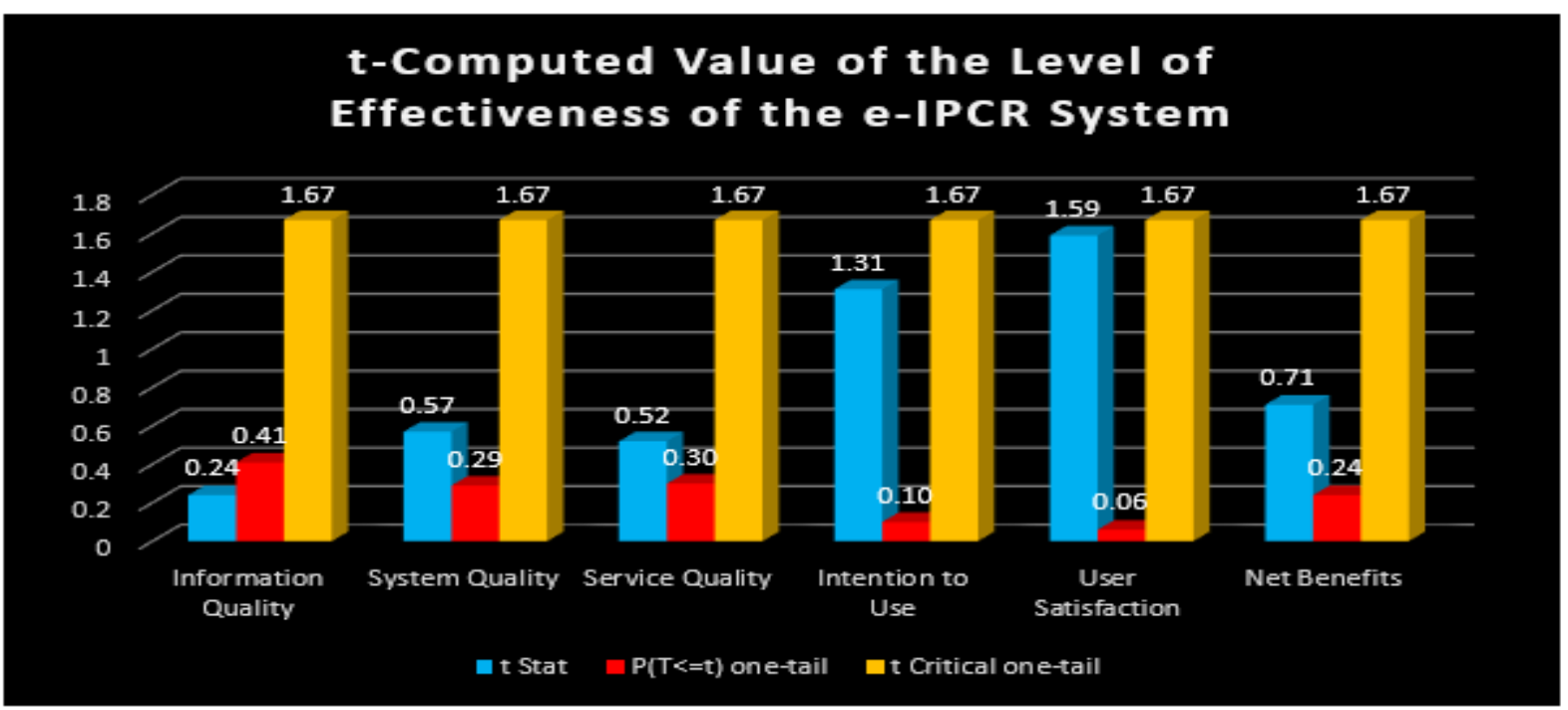

Chart 4

There is no substantial difference between the evaluation of the college deans and faculty respondents on the level of effectiveness of e-IPCR system as a tool for managing faculty performance evaluation of RMTU Main Campus Iba Zambales using the DeLone and McLean Success Model. As such, it therefore fails to reject the hypothesis.

Substantial difference between the evaluation of the college deans and faculty respondents on the level of acceptability for continuously adopting the e-IPCR system as a tool of managing faculty performance evaluation for RMTU Main Campus, Iba, Zambales.

Chart 5 below represents the substantial difference between the evaluation of the college deans and faculty respondents on the level of acceptability for continuously adopting of e-IPCR system as a tool of managing faculty performance evaluation for RMTU Main Campus, Iba, Zambales

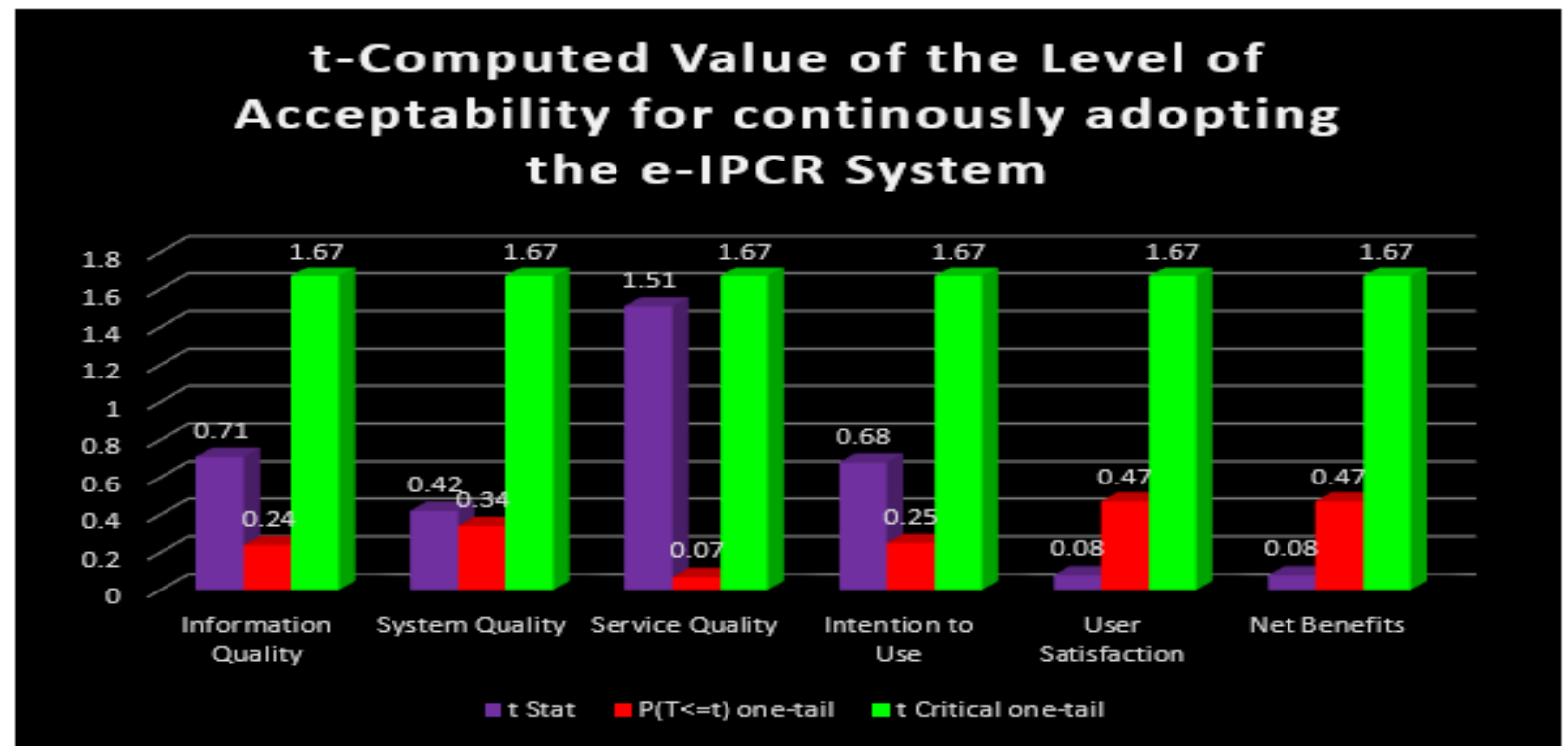

Chart 5 
There is no substantial difference between the evaluation of the college deans and faculty respondents on the level of acceptability for continuously adopting the e-IPCR system as a tool for managing faculty performance evaluation of RMTU Main Campus - Iba, Zambales using the DeLone and McLean Success Model. Therefore, it fails to reject hypothesis.

\section{Conclusions}

Based on the findings of the study stated above, the following conclusions were drawn.

1) The e-IPCR System as a tool of managing faculty performance evaluation for RMTU Main Campus is "Effective" in terms of Information Quality, Systems Quality, Service Quality, Intention to Use, User Satisfaction and Net Benefits.

2) The Level of Acceptability for continuously adopting the e-IPCR System as a tool of managing faculty performance evaluation for RMTU Main Campus is described as "Acceptable" in terms of Information Quality, Systems Quality, Service Quality, Intention to Use, User Satisfaction and Net Benefits.

3) The priority features to be integrated in the e-IPCR system according to the college dean and personnel respondents are the following:

- A system with database connected through local area networks;

- A system with link to e-copy submission of documents by the faculty for real time rating; and

- A system that generates report with comparison graph of the previous and present performance evaluations of individual faculty or by college with remarks.

4) There is no substantial difference between the levels of effectiveness of the e-IPCR system as a tool for managing faculty performance evaluation of RMTU Main Campus Iba Zambales as perceived by the college dean and faculty respondents.

5) There is no substantial difference between the levels of acceptability to continuously adopting the e-IPCR system as a tool for managing faculty performance evaluation of RMTU Main Campus Iba Zambales as perceived by the college dean and faculty respondents.

\section{Recommendations}

Based on the above-mentioned conclusions, the following are the recommendations.

1) The integration / provision of essential features would enhance e-IPCR systems effectiveness. This includes the following, in order of preference and priorities;

- A system with database connected through local area networks;

- A system with link to e-copy submission of documents by the faculty for real time rating; and

- A system that generates report with comparison graph of the previous and present performance evaluation of individual faculty or by college with remarks.

2) Upgrade infrastructure, equipment and hardware devices, for the implementation of the enhanced e-IPCR system.

3) The implementation of enhanced e-IPCR system is highly recommended to all the campuses of the university. 
[Cruz et. al., Vol.6 (Iss.8): August 2018]

(Received: July 09, 2018 - Accepted: August 18, 2018)
ISSN- 2350-0530(O), ISSN- 2394-3629(P)

DOI: 10.5281/zenodo.1403825

4) The Office Performance Commitment Review (OPCR) is should be included in the newly enhanced system.

\section{Sample Screen Shots of the e-IPCR System}

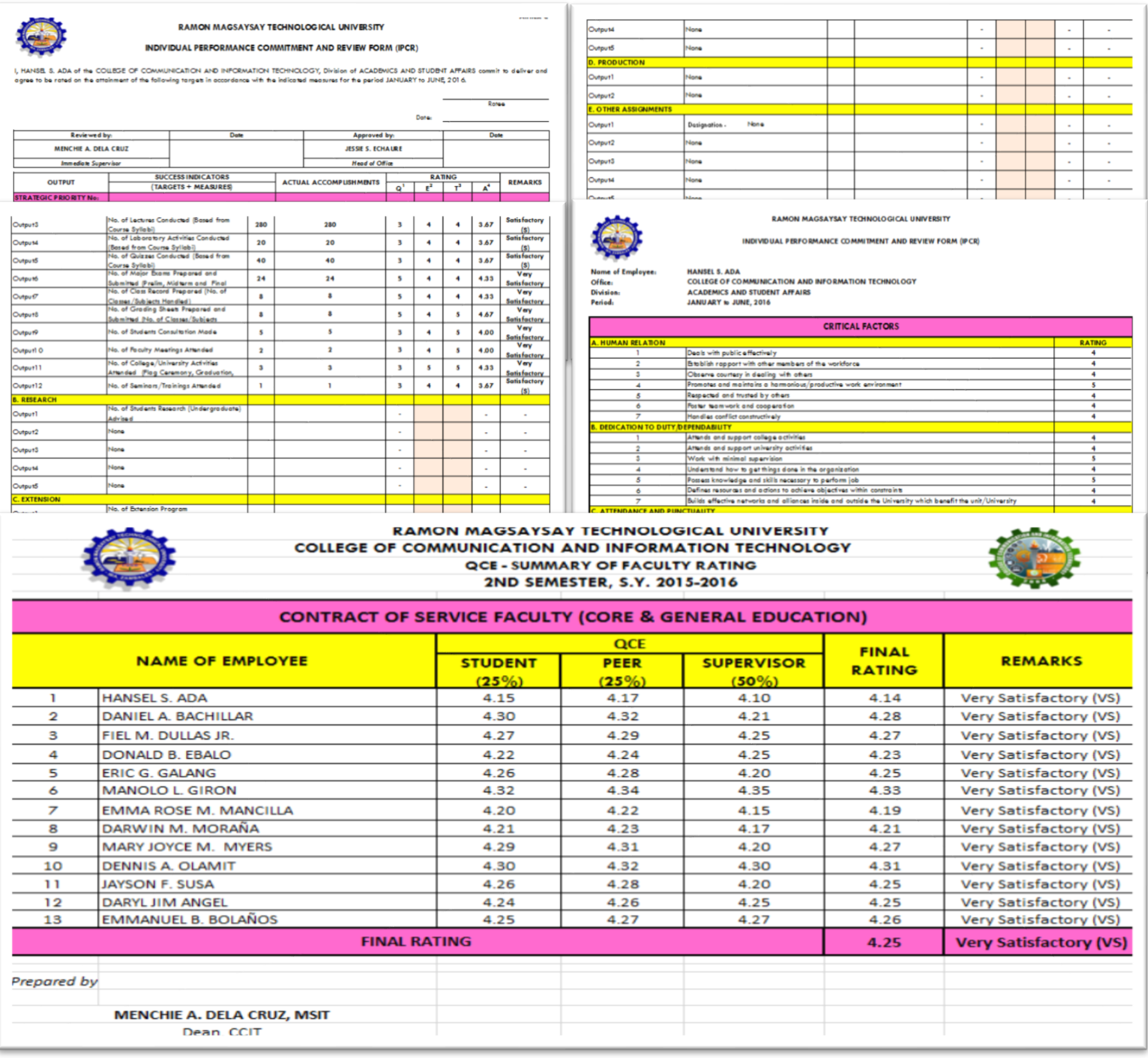

\section{References}

[1] Davis FD, Bagozzi RP, Warshaw PR. User acceptance of computer technology: A comparison of two theoretical models. Manage Sci. 1989; 35:982-1003. 
[2] DeLone, W.H., McLean, E.R. (2003): The DeLone and McLean Model of Information Systems Success: A Ten-Year Update. Journal of Management Information Systems 19 (4), 9-30

[3] DeLone, W.H., and McLean, E.R. (1992). Information Systems Success: The Quest for the Dependent Variable. Information Systems Research, 3(1), 60-95.

[4] Grover, V., Leong, S.R., Segars, A.H. (1996): Information systems effectiveness: The construct, space and patterns of application. Information \& Management 31 (4), 177 - 191

[5] Keil M, Beranek PM, Konsynski BR. Usefulness and ease of use: field study evidence regarding task considerations. Decis Support Syst. 1995; 13:75-91.

[6] Miller, Holmes (Spring 1996). "THE MULTIPLE DIMENSIONS OF INFORMATION QUALITY". Information Systems Management. 13 (2): 79-82

[7] Pearson, S.W. (1983). Development of a Tool for Measuring and Analyzing Computer User Satisfaction. Management Science, 29 (5), 530-545.

[8] Swartz, N. (2007). Data Management Problems Widespread: Organizations should regard data as their greatest asset and invest in data Management Accordingly. On the Edge: The Use \& Misuse of Information). Retrieved from www.accessmylibrary.com

[9] Szajna B. Empirical evaluation of the revised Technology Acceptance Model. Manage Sci. 1996; 42:85-92.

[10] Petter, S., DeLone, W.H., McLean, E.R. (2008): Measuring information systems success: models, dimensions, measures, and interrelationships. European Journal of Information Systems 17 (3), 236 $-263$

\footnotetext{
*Corresponding author.

E-mail address: chie_qtpie@yahoo.com
} 